\title{
Unintentional Gerrymandering: Political Geography and Electoral Bias in Legislatures
}

\author{
Jowei Chen ${ }^{1}$ and Jonathan Rodden ${ }^{2, *}$ \\ ${ }^{1}$ Department of Political Science, University of Michigan, 5700 Haven \\ Hall, 505 South State Street, Ann Arbor, MI 48109-1045, USA; \\ jowei@umich.edu \\ ${ }^{2}$ Department of Political Science and Hoover Institution, Stanford \\ University, Encina Hall West, Suite 100, Stanford, CA 94305-6044, USA; \\ jrodden@stanford.edu
}

\begin{abstract}
While conventional wisdom holds that partisan bias in U.S. legislative elections results from intentional partisan and racial gerrymandering, we demonstrate that substantial bias can also emerge from patterns of human geography. We show that in many states, Democrats are inefficiently concentrated in large cities and smaller industrial agglomerations such that they can expect to win fewer than $50 \%$ of the seats when they win $50 \%$ of the votes. To measure this "unintentional
\end{abstract}

\footnotetext{
* The authors wish to thank Micah Altman, Pablo Beramendi, Kyle Dropp, David Epstein, Andrew Gelman, Tony Hill, Nolan McCarty, Michael McDonald, Boris Shor, John Sides, and Chris Warshaw for helpful comments and suggestions.
}

Online Appendix available from:

http://dx.doi.org/10.1561/100.00012033_app

Supplementary Material available from:

http://dx.doi.org/10.1561/100.00012033_supp

MS submitted 4 April 2012; final version received 13 January 2013

ISSN 1554-0626; DOI 10.1561/100.00012033

(C) 2013 J. Chen and J. Rodden 
gerrymandering," we use automated districting simulations based on precinct-level 2000 presidential election results in several states. Our results illustrate a strong relationship between the geographic concentration of Democratic voters and electoral bias favoring Republicans.

In majoritarian political systems like the United States, the extent to which electoral support for a party translates into legislative representation is driven by the geographic distribution of votes across districts. For instance, in a set of hotly contested U.S. states including Florida, Michigan, Ohio, Missouri, Indiana, and Pennsylvania, the Democrats have had far more statewide success in winning presidential, U.S. Senate, and gubernatorial races than in winning control of state legislatures. Party strategists and pundits as well as academics (King and Gelman, 1991; Hirsch, 2003; McDonald, 2009a) have noticed that this disconnect between statewide partisanship and representation is driven by a disadvantageous distribution of Democratic voters across legislative districts. A window into this phenomenon is provided by Florida's notorious tied presidential election of November 2000, in which votes for George W. Bush outnumbered votes for Al Gore in $68 \%$ of Florida's Congressional districts.

Why does this type of electoral bias emerge? One source of bias is intentional gerrymandering, whereby district maps are drawn to favor partisan or racial groups. Another source is unintentional gerrymandering, whereby one party's voters are more geographically clustered than those of the opposing party due to residential patterns and human geography.

Ever since Elbridge Gerry proposed his famous Massachusetts district, the U.S. literature on electoral bias has been dominated by the notion of intentional gerrymandering. The machinations of politically motivated cartographers take center stage in the theory literature (e.g., Gilligan and Matsusaka, 1999; Gul and Pesendorfer, 2010) as well as in empirical studies (e.g., Abramowitz, 1983; Cain, 1985; Cox and Katz, 2002; Herron and Wiseman, 2008; McCarty et al., 2009). Likewise, studies of racial gerrymandering have used theoretical (e.g., Shotts, 2001, 2003) and empirical analyses (e.g., Brace et al., 1988; Hill, 1995; Lublin, 1997; Cameron et al., 1996; Griggs and Katz, 2005) to show that efforts at enhanced minority representation inexorably pack Democrats into relatively few districts.

A significant reform movement in the United States is predicated on the notion that observed electoral bias stems from intentional gerrymandering. 
Districting reformers in many states have advanced various statutory and constitutional proposals to prohibit partisan gerrymandering and enforce more neutral, objective criteria and procedures in the redistricting process. In Florida, for example, in response to a striking pattern of proRepublican electoral bias, a coalition of left-wing interest groups invested significant energy and resources into passing Amendments 5 and 6, which voters approved in November 2010. These ballot initiatives mandate that newly drawn congressional and state legislative districts be compact and contiguous in shape, and the initiatives prohibit redistricting plans drawn with the intent to favor either political party.

Such reforms are based on the assumption that human geography plays no significant role in generating electoral bias. Reformers are betting that the inefficient distribution of Democrats across districts in a number of states would disappear if the process of districting could only be sufficiently insulated from Republican cartographers and minority interest groups.

This article examines the possibility that human geography plays a far greater role in generating electoral bias in the United States than commonly thought. Building on existing literature, we explore the argument that Democrats are often more clustered in space than Republicans as a result of the industrial revolution, great migration, and subsequent patterns of suburbanization (Fenton, 1966; Dixon, 1968; Erikson, 1972, 2002; Jacobson, 2003; McDonald, 2009a, 2009b). This argument dovetails with the emphasis on similar aspects of human geography in the comparative literature (e.g., Johnston, 1976; Taylor and Gudgin, 1976; Gudgin and Taylor, 1979; Johnston and Hughes, 2008; Rodden, 2010).

We show that in many urbanized states, Democrats are highly clustered in dense central city areas, while Republicans are scattered more evenly through the suburban, exurban, and rural periphery. We illuminate this pattern with an in-depth case study of Florida and demonstrate that it holds up in many other states. Precincts in which Democrats typically form majorities tend to be more homogeneous and extreme than Republican-leaning precincts. When these Democratic precincts are combined with neighboring precincts to form legislative districts, the nearest neighbors of extremely Democratic precincts are more likely to be similarly extreme than is true for Republican precincts. As a result, when districting plans are completed, Democrats tend to be inefficiently packed in homogeneous districts.

This observation raises some vexing empirical questions: To what extent is observed pro-Republican electoral bias a function of human geography rather 
than intentional gerrymandering? To what extent might pro-Republican bias persist in the absence of partisan and racial gerrymandering?

The main contribution of this paper is to answer these questions by generating a large number of hypothetical alternative districting plans that are blind as to party and race, relying only on criteria of geographic contiguity and compactness. We achieve this through a series of automated districting simulations. The simulation results provide a useful benchmark against which to contrast observed districting plans. We show that in general, pro-Republican partisan bias is quite persistent in the absence of intentional gerrymandering. Moreover, consistent with our argument about human geography, we demonstrate that the highest levels of electoral bias against Democrats occur in states where Democratic voters are most concentrated in urban areas.

\section{Political Geography and the Roots of Electoral Bias in the United States}

Electoral maps from recent U.S. presidential elections illustrate clearly that in much of the United States, support for Democrats is highly clustered in densely populated city centers, declines gradually as one traverses the suburbs and exurbs, and levels off in moderately Republican rural areas. Additionally, in the rural periphery, there are scattered pockets of strong support for Democrats in smaller agglomerations associated with nineteenth century industrial activity along railroad lines, canals, lakes, and rivers, as well as in college towns.

To illustrate the relationship between population density and voting behavior, we match precinct-level results from the 2000 presidential election to precinct boundary files produced by the U.S. Census. We are able to obtain such 2000 precinct-level data for 20 states. We then generate block group estimates of election results, which we plot against population density data from the census in Figure 1. The relationship between population density and Democratic voting is generally widespread, but there is some cross-state heterogeneity. This relationship is most pronounced in the most industrialized and urbanized states, but it is less pronounced or absent in less industrialized Southern states with large rural African American populations and in relatively sparse Western states.

It is important to note that the densely populated urban block groups in the lower-right corners of the scatter plots in Figure 1 are not randomly 


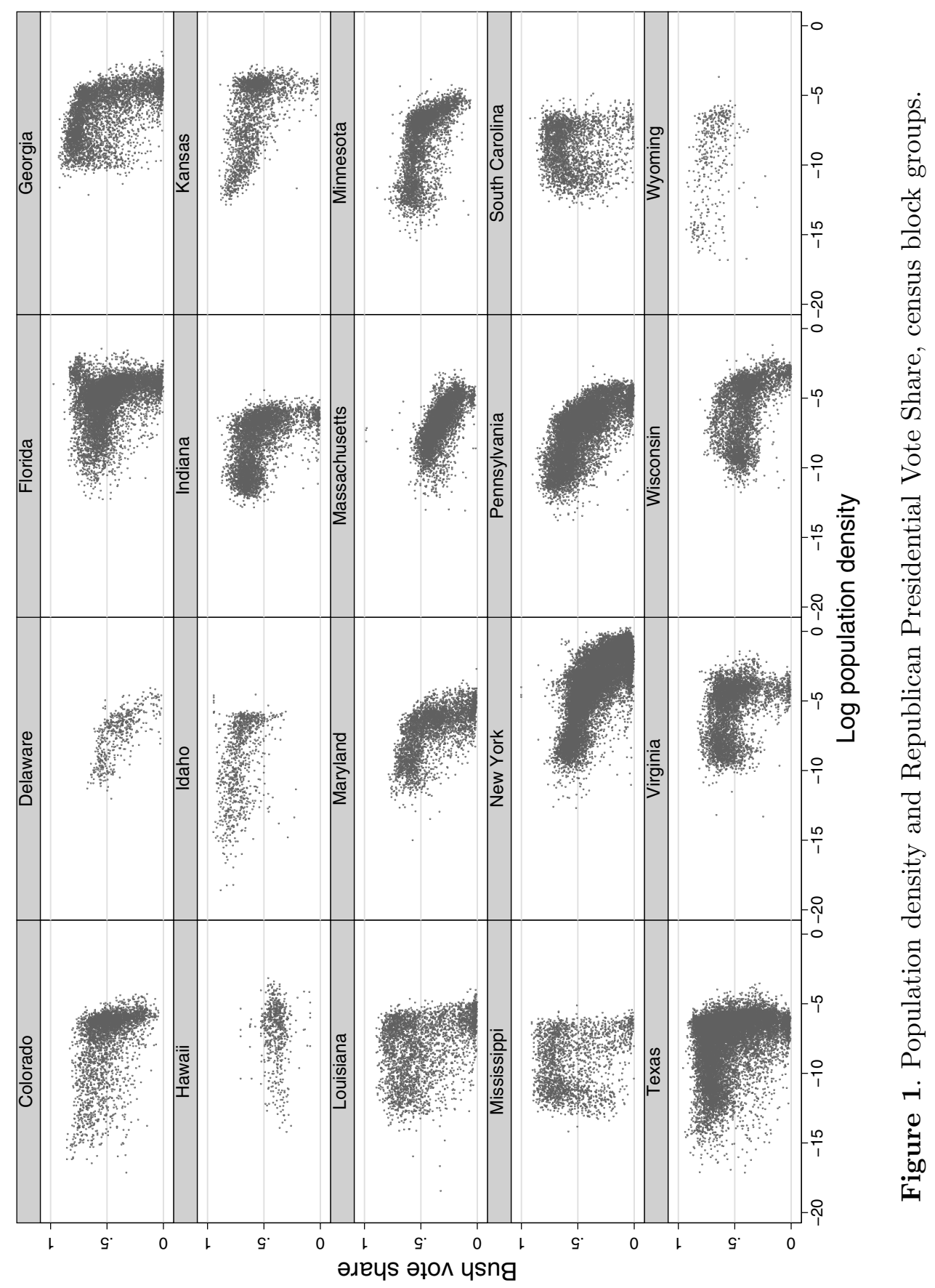




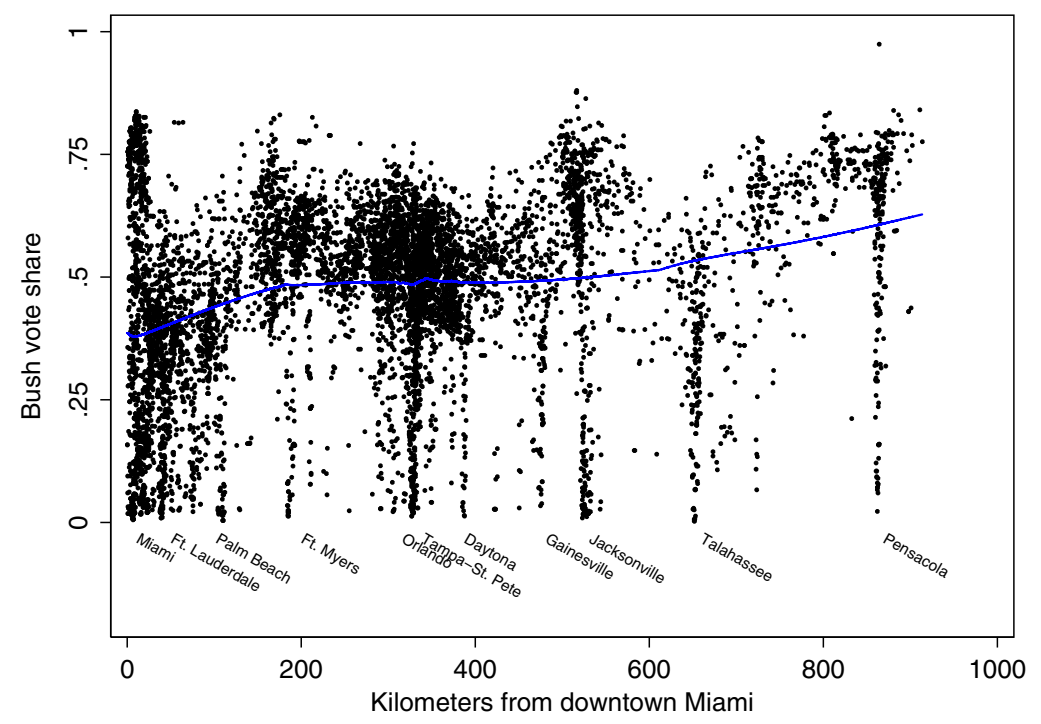

Figure 2. The spatial arrangement of partisanship in Florida.

distributed in space; many of them are in close proximity to one another. For example, support for Democrats in Florida is highly concentrated in downtown Miami and the other coastal cities to its immediate North, as well as downtown Orlando, Tampa, St. Petersburg, Daytona, Gainesville, Jacksonville, Tallahassee, and Pensacola, as well as a few other smaller railroad and college towns. The suburbs of these cities, along with rural Florida, are generally Republican, but only moderately so.

Figure 2 displays the distance in kilometers between the center of Miami's central business district and the location of every census block group in Florida. Figure 2 displays this distance on the horizontal axis, and the vertical axis displays the block group's Bush vote share. Block groups toward the right of this plot are further away from Miami, and the extreme right side of the plot depicts block groups in the Florida panhandle. The lower left corner of the plot displays the large number of overwhelmingly Democratic precincts in downtown Miami, Ft. Lauderdale, and Palm Beach. Above these urban cores in the graph are more heterogeneous suburban neighborhoods where the Bush vote share, on average, only slightly exceeds $50 \%$.

The tips of each of the other "stalactites" in Figure 2 are city centers where Al Gore's vote share in November 2000 often exceeded 90\%. In each case, as one moves outward from the city center, the Bush vote increases, and each 
city is surrounded first by a very mixed area, second by a suburban periphery that produced solid but not overwhelming support for Bush, and then finally by a rather heterogeneous but moderately Republican periphery. Analogous plots are quite similar in all of the other states that are characterized by high correlations between population density and voting in Figure 1.

These depictions illustrate two important patterns with consequences for districting. First, Democrats are far more clustered within homogeneous precincts than are Republicans. For example, while Bush received over $80 \%$ of the vote in only 80 precincts, Gore received over $80 \%$ in almost 800 precincts. Second, the stalactite shape of cities and their surroundings in Figure 2 illustrate that Democratic precincts tend to be closer to one another in space than Republican precincts. That is, the nearest neighbors of predominantly Democratic precincts are more likely to be predominantly Democratic than is the case for Republican precincts.

Some simple spatial statistics allow us to demonstrate this. First, we can identify the nearest neighbor of every precinct, defined as the precinct with the most proximate centroid, and ask whether that neighbor has the same partisan disposition. For any reasonable cut-off used to differentiate "Democratic" and "Republican" precincts (e.g., lower than 40th vs. higher than 60th percentile values of Bush share, 30th vs. 70th, etc.), we find that indeed, the nearest neighbors of Democratic precincts are significantly more likely to be Democratic than is the case for Republicans, whose neighbors are more heterogeneous.

Alternatively, rather than forcing precinct partisanship to be binary, it is useful to examine the extent to which each precinct's election results are correlated with those of its neighbors, and ask whether the extent of this spatial autocorrelation is higher in Democratic than in Republican districts. Anselin's (1995) local Moran's $I$ is well suited to this task. For each precinct $i$, the local Moran's $I$ is given by:

$$
I_{i}=\frac{Z_{i}}{m_{2}} \sum_{j} W_{i j} Z_{j}
$$

where

$$
m_{2}=\frac{\sum_{i} Z_{i}^{2}}{N}
$$

and $Z_{i}$ is the deviation of Bush share with respect to the mean across all precincts, $N$ is the number of precincts, and $W_{i j}$ is a matrix of weights with ones in position $i, j$ whenever precinct $i$ is a neighbor of precinct $j$, 


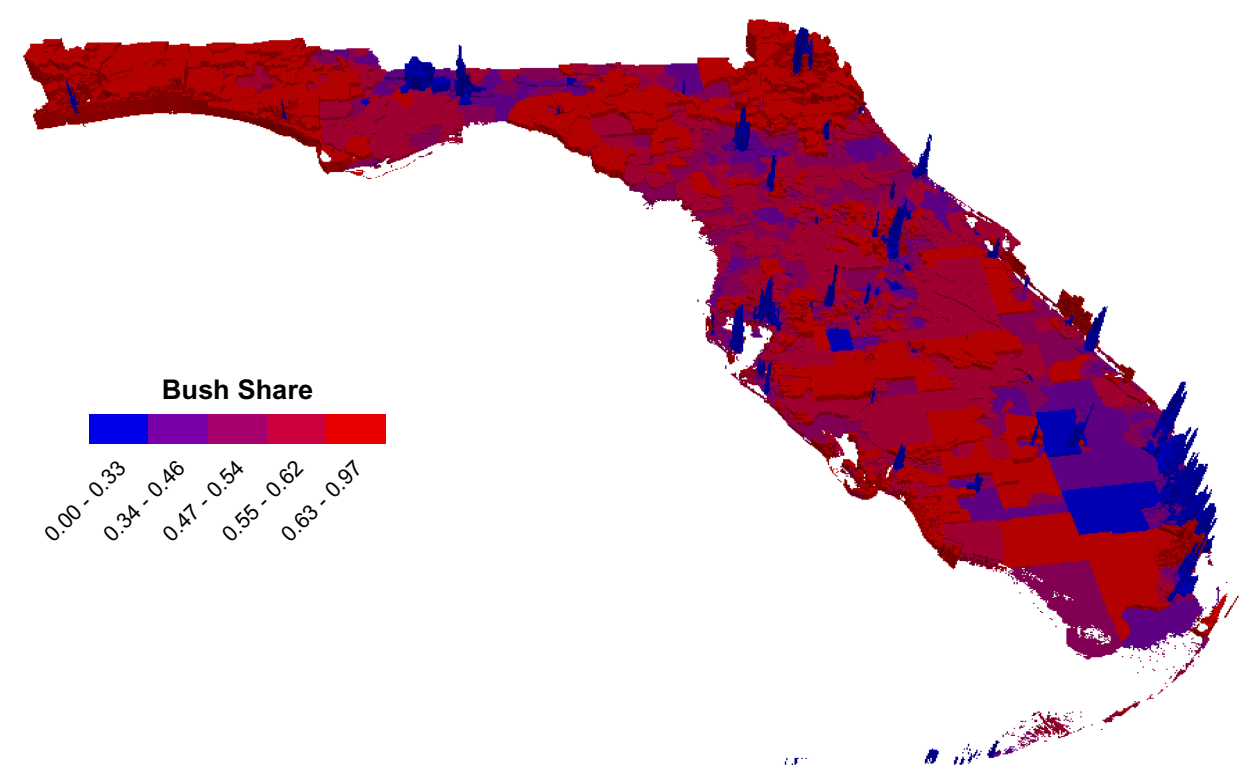

Figure 3. 2000 Bush vote share. Colors correspond to Bush vote share, heights correspond to local Moran's I.

and zero otherwise. We define neighbors as precincts that share any part of any boundaries or vertices (Queen Contiguity), although we get very similar results when using Rook contiguity or distance-based spatial weights.

Overall, $I_{i}$ is much higher for majority-Democratic precincts than for Republican precincts, indicating that Democratic precincts are far more spatially clustered. Figure 3 displays $I_{i}$ for each precinct using an extruded map, in which the height of each extrusion corresponds to the extent of spatial autocorrelation, and the color moves from blue to red as the precinct's Bush vote share increases. Figure 3 illustrates clearly that the most Democratic precincts in Florida's city centers are also those with the highest levels of local spatial autocorrelation; that is, they are surrounded by other very Democratic precincts. While there are some Republican-leaning areas of high spatial autocorrelation in little Havana, suburban Jacksonville, and the Panhandle, Republican precincts overall tend to be located in more heterogeneous neighborhoods.

The process of building electoral districts involves someone - incumbent politicians, judges, or districting boards — stringing together contiguous census blocks. Drawing on the rhetoric of reform advocates, let us consider a districting process in which these census blocks are assembled without 
political or racial manipulation. To illustrate, consider a process of randomly selecting one of the dots in Figure 2 and randomly connecting it with surrounding dots until enough dots have been selected to form a state legislative district or Congressional district.

This process is likely to undermine the representation of Democrats for three reasons. First, suppose that the initial seed is a precinct in one of the stalactites representing Florida's large cities, such as Miami, Jacksonville, or Tampa. Such a city is sufficiently large that this process will likely combine extremely Democratic districts with other extremely Democratic districts, thereby forming a district that is overwhelmingly Democratic.

Second, outside of little Havana, it is difficult to find a Florida precinct that, when randomly chosen as the initial seed, would produce an analogously extreme Republican district. In addition to being more internally heterogeneous, Republican precincts tend to be located in heterogeneous suburban and rural areas of the state where their nearest neighbors are more diverse. For instance, suppose the initially chosen precinct is rural and extremely pro-Republican. If one strings together neighboring precincts until reaching the population threshold for a district, this will usually require the inclusion of some rather heterogeneous precincts, often including pockets of Democrats in small cities or towns and on the fringes of larger cities.

A third reason concerns the locations of small Democratic-leaning towns throughout Florida. Although dense, pro-Democratic cities are often combined together to form Democratic districts along the Eastern Coast, there are also small, isolated, inland pockets of Democratic voters in the manufacturing and transportation agglomerations that sprung up along railroad tracks in the nineteenth century, such as Ocala or Pensacola, and the college towns of Tallahassee and Gainesville. When the size of districts is large relative to these small clusters of Democrats, these towns are often subsumed into predominantly rural, moderately Republican districts, thus wasting Democratic votes in districts that are won by Republicans.

The roots of unintentional gerrymandering in Florida can be summarized as follows. The complex process of migration, sorting, and residential segregation that generated a spatial distribution of partisanship has left the Democrats with a more geographically concentrated support base than Republicans. When compact, contiguous districts are imposed onto this geography without regard for partisanship, the result will be a skew in the distribution of partisanship across districts such that with $50 \%$ of the votes, Democrats can expect fewer than $50 \%$ of the seats. 


\section{Automated Districting and Electoral Bias}

Studies of electoral bias typically flow from the normative premise that in a two-party system, a party with $50 \%$ of the votes should receive $50 \%$ of the seats. Empirical studies use either aggregate data over several elections or transformations of district-level data from individual elections to examine the seat share that would be obtained by the parties under a hypothetical scenario of a tied election. Our goal is different. Rather than examining the bias associated with existing districting plans, many of which were undoubtedly influenced by efforts at partisan and racial gerrymandering, we seek to estimate the electoral bias that would emerge under hypothetical districting plans that are not intentionally gerrymandered.

Rather than using information from existing districts to simulate hypothetical tied elections, we use information from precinct-level election results, and we perform a large number of automated, computer-based simulations of legislative districting plans. Our computer simulations construct these districting plans in a random, partisan-blind manner, using only the traditional districting criteria of equal apportionment and geographic contiguity and compactness of single-member legislative districts. For each of these simulated districting plans, we calculate the Bush-Gore vote share of each simulated single-member district, and we use this vote share to determine whether the district would have returned a Democratic or Republican majority. We begin with Florida's 2000 presidential race because of its unique quality as a tied election.

Since the early 1960s, scholars have suggested automated districting as a solution to the problem of partisan gerrymandering (e.g., Vickrey, 1961; Weaver and Hess, 1963; Nagel, 1965). More recently, scholars have used hypothetical districting experiments to examine partisan polarization (McCarty et al., 2009), partisan representation (Altman, 1998), and the impact of various districting criteria (McDonald, 2009b). These previous studies have often used automated redistricting in order to obtain a baseline against which to detect the intentions of those drawing the lines. Cirincione et al. (2003) use a simulated districting algorithm to detect racial gerrymandering in South Carolina's congressional districting plan, while Altman and McDonald (2004) propose an enhanced method of this algorithm for detecting partisan gerrymandering. Johnston and Hughes (2008) apply an automated districting algorithm in Brisbane, Australia in order to gain a baseline against which to compare the boundaries chosen by neutral 
commissioners. Extending this past work, we use simulations to examine the electoral consequences of a hypothetical districting process without any intentional partisan or racial gerrymandering.

As of the November 2000 election, Florida consisted of 6,045 voting precincts. These precincts are the smallest geographic unit at which election results are publicly announced, so we use the precinct as the building block for our simulations. Hence, a complete districting plan consists of assigning each one of Florida's precincts to a single legislative district. Florida voters cast 5.96 million Presidential election ballots in 2000, so the average precinct cast a total of 986 presidential votes.

Our goal is to design a districting algorithm that uses only traditional geographic criteria of the kind favored by reform advocates. Our challenge is to guarantee equal apportionment of population while requiring geographic contiguity for all simulated districts, paying no attention to either voter partisanship or any demographic information other than simple population counts. Another concern is geographic compactness. Many districting reform proposals include explicit (if vague) compactness requirements, and reformers sometimes equate compactness with fairness. Moreover, an algorithm that makes no attempt to achieve compactness might create districts that seem too far removed from the real world. On the other hand, if we build some strict compactness criteria into the algorithm, we run the risk that any pro-Republican bias observed in the simulated plans could be driven exclusively by compactness criteria that, for instance, force the most extreme Democratic precincts in Miami to be joined together.

Our approach is to experiment with alternative algorithms that approach compactness in different ways or ignore it altogether. Due to space constraints, we focus here on two algorithms: one that aims for compactness and one that does not.

Our procedure for simulating compact districts is as follows. Suppose that we begin with $n$ precincts and wish to create $d$ districts with equal population.

(1) To begin the simulation procedure, each of the $n$ precincts represents a single district. Hence, there are $n$ districts, each containing only one precinct at the outset.

(2a) Randomly select one of the $n$ districts and denote it as district $i$.

(2b) Among the neighboring districts that border district $i$, select the one that is geographically closest, and denote it as district $j$. Geographic 
proximity is measured as the distance between district $i$ 's centroid and the respective centroids of $i$ 's neighboring districts.

(2c) Merge district $i$ together with district $j$ in order to form a single, new district. There are now $n-1$ total districts remaining.

Steps 2a through 2c are repeated until the total number of districts is exactly $d$. At this point in the procedure, these $d$ districts are geographically contiguous and reasonably compact, due to the nearest distance criterion employed in step $2 \mathrm{~b}$. However, the districts are not guaranteed to be equally populated. Hence, repeated iterations of steps 3a through $3 \mathrm{c}$ are designed to achieve an equitable distribution of population across the simulated districts. These steps iteratively reassign precincts to different districts until equally populated districts are achieved.

(3a) Among all pairs of districts that border one another, identify the pair with the greatest disparity in district population. Within this pair, let us denote the more populated district as $i$ and the less populated district as $j$.

(3b) Identify the set of all precincts currently within district $i$ that could be reassigned to district $j$ without violating the geographic contiguity of either district $i$ or $j$.

(3c) For each precinct $p$ satisfying the criterion in step $3 \mathrm{~b}$, define $D_{p}$ as precinct $p$ 's geographic distance to the centroid of district $i$, minus precinct $p$ 's distance to the centroid of district $j$.

(3d) Among the set of precincts satisfying the criteria in step 3b, select the precinct, $p$, with the highest value of $D_{p}$. Reassign this precinct from district $i$ to district $j$.

Steps 3a through 3d are repeated until every district's population is within $5 \%$ of the ideal district population. The ideal district population is defined as the statewide population, divided by $d$, the total number of districts. Hence, these steps iteratively reassign precincts in order to achieve equal population across the districts. However, steps $3 \mathrm{c}$ and $3 \mathrm{~d}$ perform such precinct reassignment in a manner that preserves the geographic compactness of the districts. Compactness is preserved because step $3 \mathrm{~d}$ generally reassigns a precinct that was geographically distant from its old district's centroid and geographically close to the centroid of its new district. 
In order to simulate non-compact districts, steps 1 and $2 \mathrm{a}$ are performed in the same manner as in the compact districting algorithm. The procedure for non-compact districts then proceeds as follows:

(2b) Select one of district $i$ 's bordering districts at random and denote it as district $j$.

(2c) Merge district $i$ together with district $j$ in order to form a single, new district. There are now $n-1$ total districts remaining.

Steps 2a through 2c are repeated until the total number of groups is exactly $d$. At this point in the procedure, these $d$ districts are geographically contiguous but not guaranteed to be equally populated. Hence, repeated iterations of steps $3 \mathrm{a}$ through $3 \mathrm{c}$ are designed to achieve an equitable distribution of population across the simulated districts.

(3a) Identify the most populated district and denote it as district $i$.

(3b) Randomly select one of the precincts lying within district $i$ and denote it as precinct $p$.

(3c) If precinct $p$ can be reassigned from district $i$ to a new district without violating the geographic contiguity of either this new district or district $i$, then reassign $p$ to this new district. If two or more new districts satisfy this criterion, then reassign precinct $p$ to one of these new districts at random.

Steps 3a through 3c are repeated until every district's population is within $5 \%$ of the ideal district population. The ideal district population is defined as the statewide population, divided by $d$, the total number of districts.

In order to help illustrate the output of these simulations, the Appendix displays sample maps of both compact and non-compact plans for Florida's

25 Congressional districts, as well as maps that zoom in on Miami and Jacksonville.

\section{Simulation Results}

For each procedure, we perform 25 simulations of Florida districting plans for each of a range of reasonable legislature sizes, ranging from 2 to 200 districts. For each simulation, we can simply aggregate the precinct-level Bush-Gore vote counts within each district and count up the number of districts in 

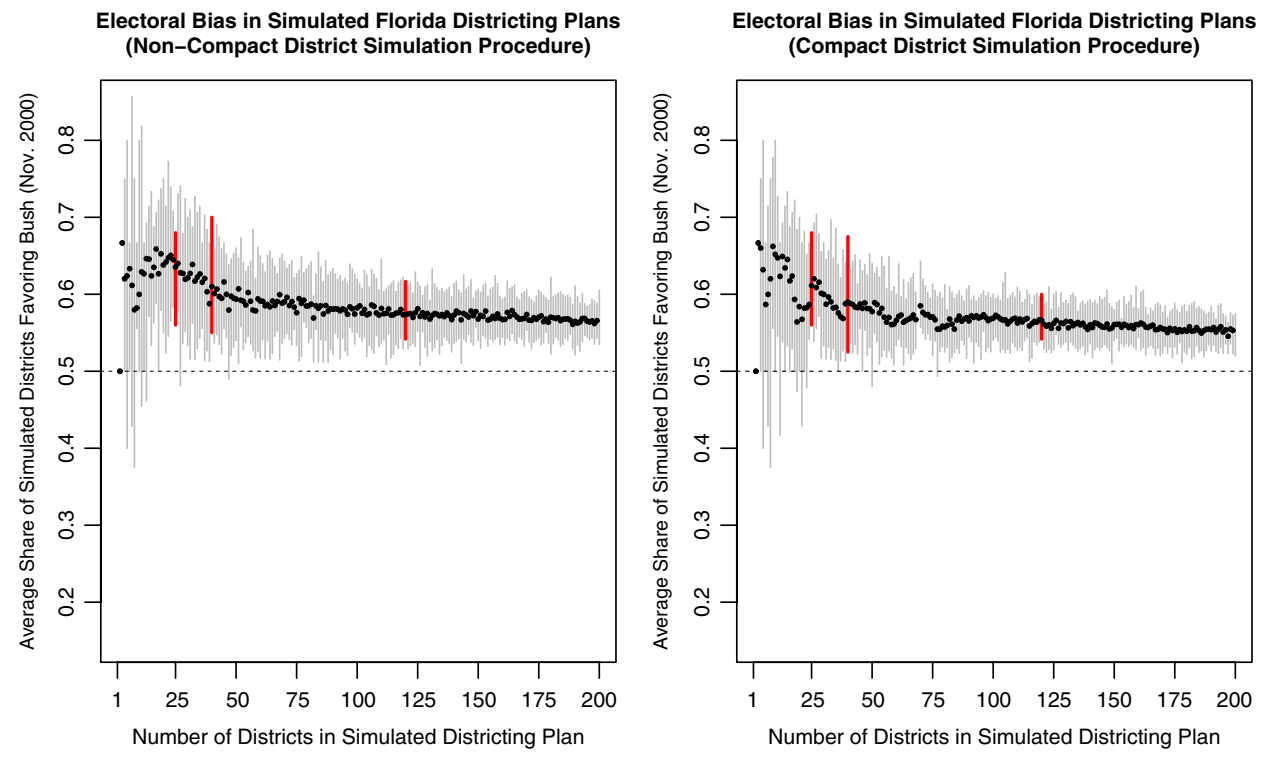

Figure 4. Republican electoral bias in simulated Florida districting plans.

Note: Black dots indicate the average share of simulated districts that have pro-Bush majorities in the simulated plans. Gray bars depict the entire range of pro-Bush district shares that were observed across all simulations for each given legislature size. Red bars depict the range of simulated outcomes for legislatures of 25 districts (Florida's Congressional Delegation), 40 districts (the Florida State Senate), and 120 districts (the Florida State House).

which Bush received a majority. The expectation is that if there is no partisan bias, the average share of pro-Bush districts should be around $50 \%$.

Our simulations reveal pro-Republican bias in the partisan distribution of seats in any realistically sized legislature; that is, significantly over onehalf of the legislative seats have Republican majorities. Figure 4 summarizes the distribution of seat shares produced under our simulations. The left panel presents results using the non-compact procedure, and the right panel reports results for the compact procedure. In this figure, the horizontal axis represents the number of single-member districts in each simulated plan. The vertical axis reports the percentage of these districts that have Republican majorities. For each different hypothetical legislature size, the dot represents the average share of simulated districts with pro-Bush majorities across all simulated plans, and the gray bars depict the entire range observed across all simulations for each given legislature size. The red colored 
bars depict the entire range of simulated outcomes for legislatures of 25 districts (Florida's Congressional Delegation), 40 districts (the Florida State Senate), and 120 districts (the Florida State House).

The figure illustrates, for example, that when we conducted random simulations that divided Florida into 25 districts using the compact procedure, Republicans won an average of $61 \%$ of the seats. The most biased of the simulated plans gave the Republicans $68 \%$ of the seats, and the least biased plan gave them $56 \%$. Overall, this plot illustrates the significant proRepublican bias that results from a districting procedure that is based solely on geography and population equality. Moreover, this result is not driven by the compactness of the simulated districts. The results are just as striking when we use the non-compact simulation procedure.

We find that the real-life districting plans enacted by the Republicancontrolled Florida legislature in 2002 are all within the range of districting plans produced by our simulation procedures. For example, in 2002, the state legislature enacted a Congressional districting plan in which Bush voters outnumbered Gore voters in 17 out of 25 districts, or $68 \%$. This level of pro-Republican electoral bias falls just within the tail of the distribution of electoral biases produced across all of the randomly simulated, compact districting plans (56-68\%), as illustrated in Figure 4. Hence, because the enacted districting plan falls within the range of plans produced by our compact districting procedure, we are simply unable to prove beyond a doubt that the enacted districting plan represents an intentional, partisan, Republican gerrymander.

Both panels of Figure 4 show that a legislature consisting of only two single-member districts will always have exactly one Democratic and one Republican seat, a result that follows naturally from Florida's 50-50 Bush-Gore vote share. But as the legislature grows in size, the partisan division of legislative seats quickly begins to favor the Republicans. When the simulated legislature has 25 seats - the size of Florida's Congressional delegation after the 2000 reapportionment - Republicans win an average of $61.2 \%$ of the districts when we use the compact procedure and $63.5 \%$ of the districts when we use the non-compact procedure.

As the size of the legislature increases further, some of the medium-density Democratic clusters in suburbs and small towns that had previously been subsumed in their surrounding Republican peripheries begin to win their own seats, and thus the Republican seat share slowly declines. However, a striking result is that the Republicans always continue to control over 
one-half of the total seats. For any districting plan of realistic size, the pro-Republican bias exhibited in our simulations is significant. With only a few exceptions, the entire range of simulations produces a hypothetical legislature with a solid Republican majority in spite of the tied election.

To provide a closer illustration of the distribution of districting plans produced by the simulations, we conduct 250 independent simulations in which Florida is divided into 25 congressional districts using the non-compact procedure. Figure A6 in the Online Appendix depicts the partisan breakdown of districts produced under these 250 simulations.

This figure illustrates that all of the 250 simulated plans result in pro-Republican electoral bias: In each plan, at least 14 of the 25 districts (56\%), and as many as 19 of the 25 districts (76\%), have a pro-Bush majority. Moreover, the figure reveals that the distribution of partisan bias across the simulations follows a normal distribution. Most of the simulations resulted in the production of 15,16 , or 17 pro-Bush districts. Drawing 14 or 18 proBush districts was a rarer outcome, and only an exceedingly small number of simulations produced as many as 19 Bush-leaning districts. Hence, these simulations demonstrate that a range of partisan outcomes is achievable under the simulations, but most of the simulations result in a predictable partisan distribution of seats that indicates significant pro-Republican electoral bias.

\section{A Closer Look at Political Geography}

Next, we use the simulation results to take a closer look at political geography as an explanation for this persistent Republican advantage. In Figure 5, we present the results of 200 independent random simulations in which Florida is divided into 25 districts.

Each plotted point in Figure 5 represents one of Florida's 6,045 precincts, and we plot high, medium, and low density precincts separately, referring to them loosely as urban, suburban/town, and rural. For each plotted point, the horizontal axis measures the partisanship of the precinct, as measured by Bush-Gore vote share in November 2000. The vertical axis measures the average partisanship of the 200 simulated districts to which the precinct was assigned during our simulations.

The patterns of spatial autocorrelation reported above give rise to the generally positive correlation between the partisanship of a precinct and the 

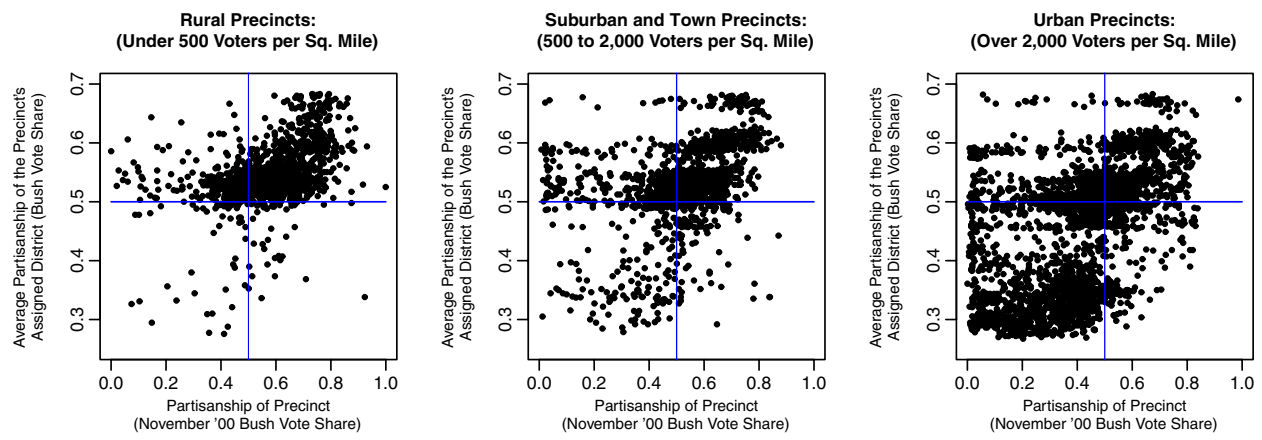

Figure 5. The partisanship of precincts' assigned districts.

Note: Each point represents a single Florida precinct. The horizontal axis indicates the precinct's partisanship, as measured by George Bush's November 2000 share of the twoparty vote. The vertical axis measures the average partisanship (George Bush vote share) of the simulated district to which the precinct was assigned. This measure is based on 25 independent random simulations of dividing Florida into 40 Senate districts, using the non-compact simulation algorithm.

partisanship of the legislative district to which the precinct was assigned. In other words, pro-Bush precincts are typically assigned to pro-Bush districts. In particular, the left and middle plots reveal that outside of dense city centers, pro-Bush precincts were almost always assigned to majority-Bush districts. Hence, the lower-right quadrants of these plots — where proRepublican precincts are assigned to majority-Democratic districts - are generally empty.

By contrast, majority-Gore precincts outside of dense urban neighborhoods are often in the upper-left quadrant of the plots. In other words, rural, small town, and suburban precincts that lean Democratic are often subsumed into moderately Republican districts. As described above, there are isolated pockets of support for Democrats in African-American enclaves in the suburbs of big cities and in smaller towns with a history of railroad industrialization or universities. However, these Democratic pockets are generally surrounded by Republican majorities, thus wasting these Democratic votes. As a result, the Democrats are poorly situated to win districts outside of the urban core.

Figure 5 illustrates that pro-Gore precincts in urban areas are generally assigned to overwhelmingly Democratic districts in our simulations. There is a large cluster of observations at the bottom of the lower-left 
quadrant of the bottom graph, indicating that Democratic precincts are assigned to extremely Democratic districts. By contrast, there are very few corresponding Republican precincts in the extreme upper right of any of the plots. Taken together, these plots show that because of their geographic support distribution, Democrats not only waste more votes in the districts they lose, but they also accumulate more surplus votes in the heavily Democratic districts they win. These two phenomena explain the rather extreme pro-Republican bias revealed by our simulations.

\section{Does Geography Constrain Partisan Gerrymandering?}

Taken together, the simulation results presented thus far suggest that residential geography alone generates significant partisan bias in Florida's districting plans. As Figure 4 illustrates, almost the entire range of simulated districting plans for every reasonable legislature size produces at least some pro-Republican bias. Among all of the randomly simulated plans consisting of 25 districts (U.S. Congressional delegation), 40 districts (Florida Senate), and 120 districts (Florida House), not a single simulated plan produces at least as many Gore-leaning districts as Bush-leaning districts. Hence, both the compact and the non-compact simulation procedures are unable to produce a single Congressional, Senate, or House districting plan for Florida that is either neutral or pro-Democratic in its distribution of seats. This finding reflects the significant pro-Republican bias in Florida that results from the geographic constraint that each district must be contiguous, even if non-compact district shapes are permitted. Our simulation results show that this contiguity requirement alone is sufficient to consistently produce pro-Republican districting outcomes in Florida.

Could a sufficiently creative Democratic gerrymander work around these geographic constraints and produce a neutral or pro-Democratic districting plan in Florida? In theory, it seems that a clever Democratic cartographer might generate radial districts emanating from the city centers so as to break up the major agglomerations and create snake-like districts to connect some of the smaller cities. Such a hypothetically contorted districting arrangement would possibly neutralize the inherent Republican advantages in geographic districting. Is such a hypothetically neutral or pro-Democratic gerrymander achievable in real-life practice? 
First, the key finding of our simulation results is that for the Florida Congressional, Senate, or House districts, our two simulated districting procedures are unable to produce a single districting plan that is neutral or pro-Democratic in terms of electoral bias. Hence, a real-life Democratic gerrymanderer would have to draw districting maps with even more creativity than our simulated non-compact districting plans in order to achieve a hypothetically neutral outcome. Moreover, human geography makes the task of a Democratic cartographer far more difficult than that facing a Republican-favoring cartographer, whom we have shown can do strikingly well by literally choosing precincts at random.

Second, to determine whether an electorally neutral districting plan in Florida is achievable in real-life practice, we examine the districting plans proposed by Democrats in the state legislature. Even though Florida's state legislature was controlled by the Republican Party during the 2002 redistricting cycle, Democratic legislators are nevertheless permitted to propose their own districting plans, and many did so in 2002. We examine these Democrat-proposed districting plans in order to measure how the most Democrat-favorable districting proposals fared in terms of electoral bias.

Specifically, we obtained district-level statistics for every proposed districting plan submitted to the Florida Senate during the 2002 redistricting cycle. To see how these real-world districting proposals compare against our non-compact, simulated districting plans, Figure 6 displays the number of Bush-leaning districts in the Congressional (Figure 6A) and Florida Senate (Figures 6B) districting plans adopted by the Republican-dominated legislature in 2002. Additionally, Figure 6 also displays the number of Bush-leaning districts in each of the alternative districting proposals submitted during the redistricting process by various Republican legislators, by various Democratic legislators, and by the League of Women Voters (hereinafter: LWV) in the Florida legislature. ${ }^{1}$

Figure 6 displays the share of majority-Republican seats generated by each proposed plan and each computer-simulated plan, as well as a histogram displaying the distribution of Republican seat shares generated by 100 of our simulations. Figure 6A displays plans for the Florida delegation

1 The Florida Senate provides information on all plans submitted to the Senate Committee on Reapportionment by Senators or the public at archive.flsenate.gov, accessed on September 20, 2012. 


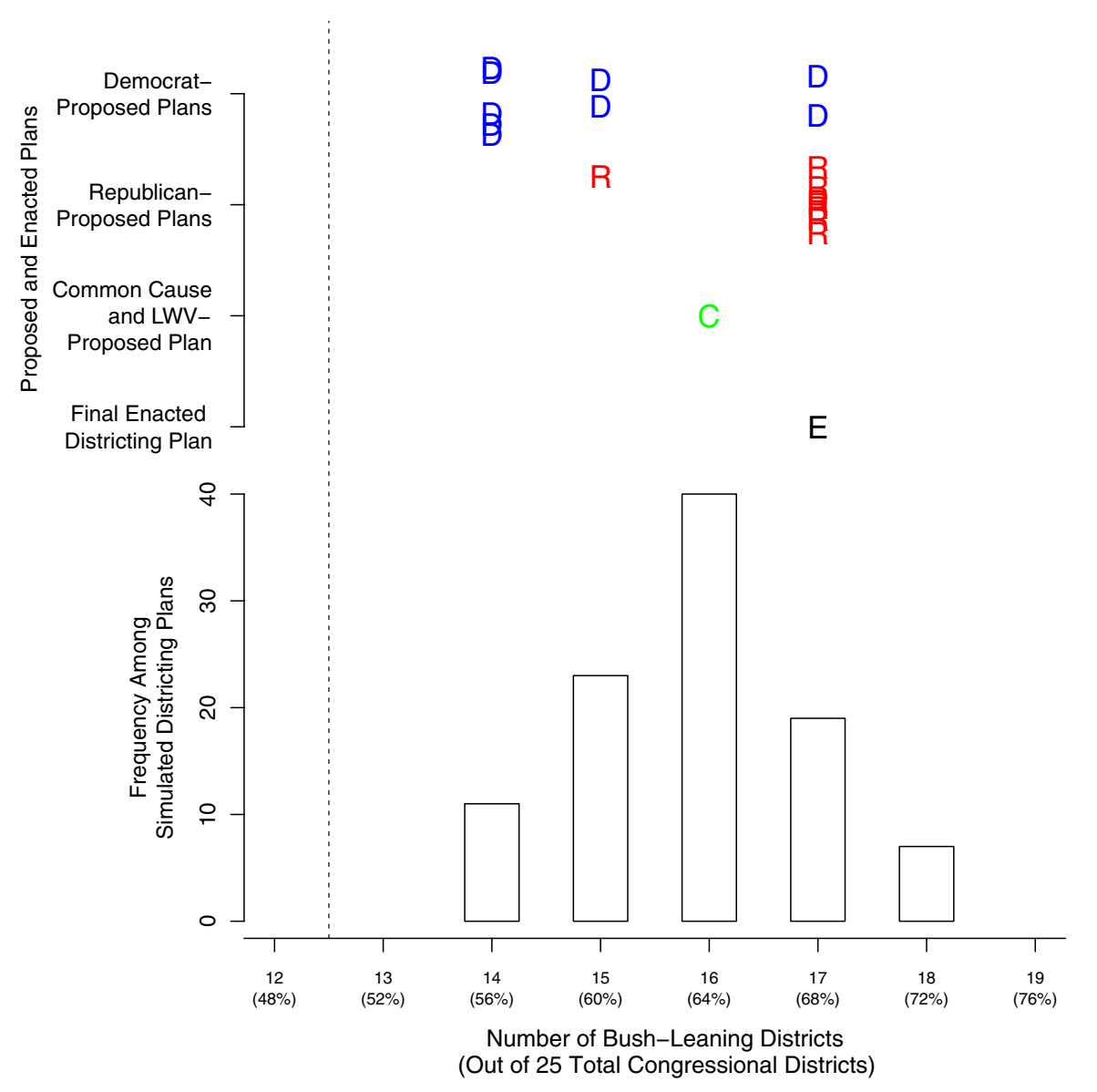

Figure 6A. Enacted, proposed, and simulated districting plans for Florida's 25 congressional districts.

Note: Proposed plans include all Congressional districting plans submitted for consideration to the Florida State Senate Committee on Reapportionment in 2002.

to the U.S. House, and Figure 6B displays plans for the Florida Senate. In terms of electoral bias, every one of the submitted plans falls well within the range of the simulated districting plans. Not surprisingly, the Republican plans tend to produce larger Republican majorities than Democratic or LWV plans, but remarkably, not a single unbiased or pro-Democratic plan was submitted by any of the Democratic legislators. Of course, we cannot conclude from Figure 6 that Democrats submit biased plans solely because 


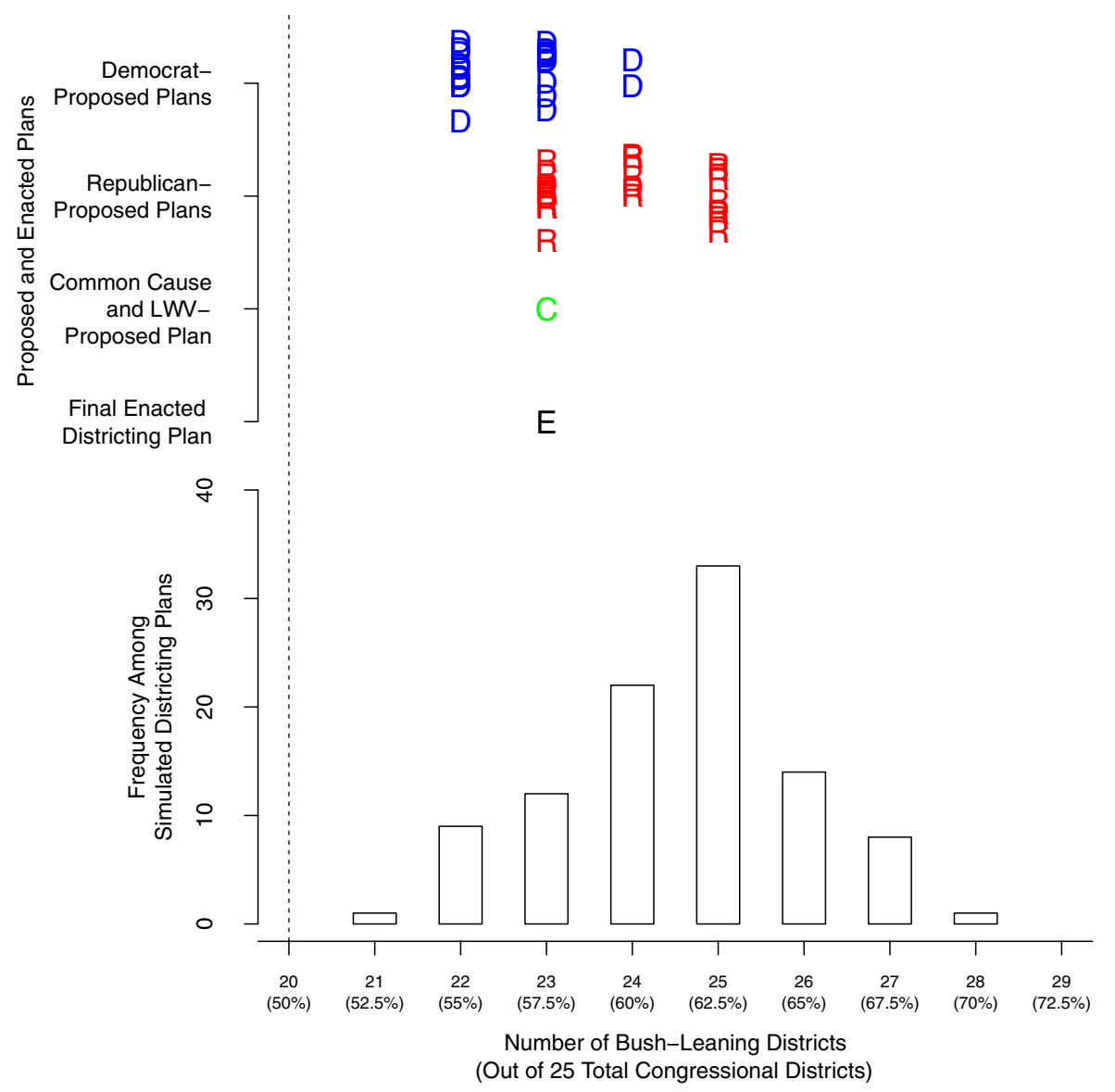

Figure 6B. Enacted, proposed, and simulated districting plans for Florida's Senate (40 districts).

Note: Proposed plans include all Senate districting plans submitted for consideration to the Florida State Senate Committee on Reapportionment in 2002.

of the constraints generated by human geography. However, at a minimum, Figure 6 suggests that the level of bias produced in the real world of strategic partisan cartographers, courts, and the Voting Rights Act is not radically different from that produced by human geography alone.

We acknowledge, however, that various political considerations may have influenced the drawing of the various Democrat-submitted plans. For example, important considerations for Democratic cartographers include 
minority representation and protection of incumbents, especially those incumbents submitting the districting proposals. An additional possibility is that Democratic mapmakers understood that a pro-Democratic redistricting plan would never secure passage in the Republican-controlled state legislature; hence, perhaps only plans with built-in Republican bias were even worth submitting.

\section{Simulation Results across U.S. States}

The most striking result thus far is the rather consistent size of the proRepublican bias in Florida; additionally, much of this bias would have occurred with a simple, random districting scheme that is blind to race or partisanship. This finding raises at least two broad questions. First, to what extent does an urban concentration of Democrats generate a similar political geography of electoral bias in other states? Second, building upon Figure 6 , to what extent does the electoral bias that would be generated by our automated districting algorithm track electoral bias observed in actual districting plans?

In order to provide the necessary cross-state perspective, we have linked November 2000 precinct-level data reported by county governments with corresponding GIS boundary files provided by the U.S. Census Bureau. The reprecincting and the use of completely different precinct identifiers in the two data sets make this a difficult challenge. While improved coordination between the census department and state election officials will soon allow for a more complete data set for more recent elections, for the November 2000 elections we have been able to match 20 states. We have applied exactly the same automated districting algorithm introduced above and produced graphs like those in Figure 4.

The only difference is that because elections in other states were not tied, before performing the simulations we applied a uniform swing to the precinct-level results in order to examine the seat share in a "hypothetical" tied election. We then calculate the average bias estimates across all simulations corresponding to the number of districts in each state's lower chamber, its upper chamber, and its U.S. Congressional delegation. A useful feature of the 2000 presidential election is the fact that it was very close in a number of states, so that the uniform swing used to achieve a hypothetical tie is not 
a far stretch of the imagination. However, in consistently lopsided states like Massachusetts or Oklahoma, close statewide elections are less frequent.

Figure 1 revealed that the extent to which Democrats are spatially concentrated in urban areas varies considerably across states. We capture this heterogeneity in a simple way by using block group-level data and regressing, state by state, the Democratic vote share in the 2000 presidential election on logged population density, weighting by the block group's population. The coefficient from this regression is displayed on the horizontal axis of the first panel of Figure 7. The vertical axis displays the average estimated Republican vote share obtained from 50 simulations of the state's Congressional and state legislative districts. Observations above 0.5 indicate that on average, the districting algorithm produced districts that would turn tied elections into Republican legislative majorities.

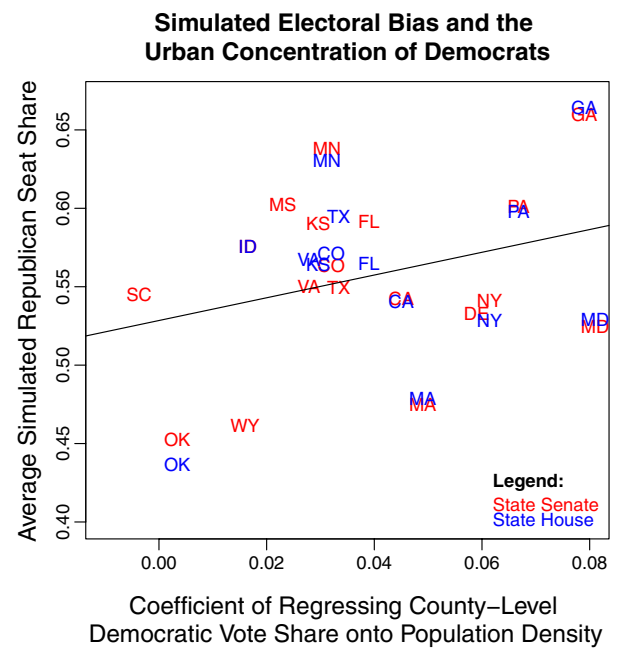

(a)

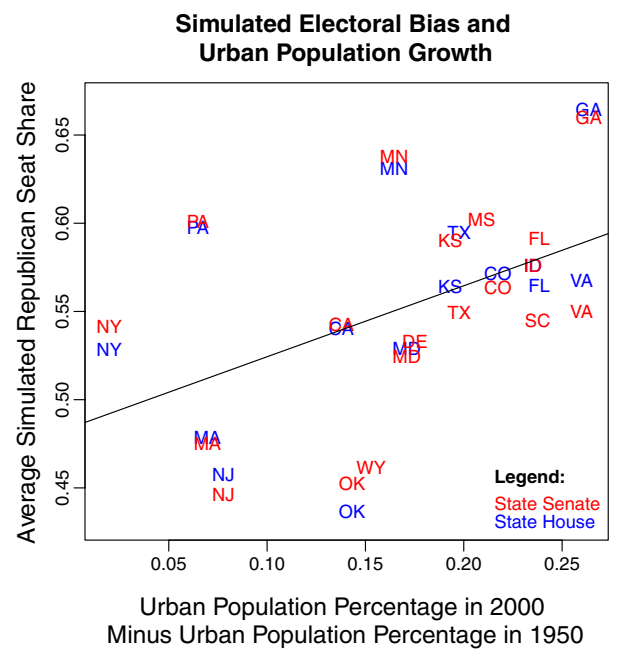

(b)

Figure 7. Simulated electoral bias in state legislatures and the urban concentration of democrats.

Note: The solid lines represent least-squares regression fits. The horizontal axis in the left plot is measured as the estimated coefficient of population density when county-level Gore (November 2000) vote share is regressed onto county-level population density within each state. The vertical axis represents the simulated electoral bias for state legislative chambers, measured as the percentage of simulated congressional districts with Republican majorities when the statewide Republican vote share is exactly $50 \%$. 
Figure 7 suggests that Florida is not an outlier. The correlation between population density and Democratic voting is even higher in several other states, and in most of them, the simulations consistently produced similar or even higher levels of pro-Republican bias than in Florida. Average bias in favor of Republicans is substantial - surpassing $5 \%$ of legislative seats - in around half the states for which simulations were possible. It appears that in some of the largest and most urbanized U.S. states, even without overt racial or partisan gerrymandering, the Democrats are at a disadvantage in translating votes to seats simply because their voters are inefficiently clustered in urban areas. According to the simulations, this problem is less severe for the Democrats in Western and Southern states, where their voters are more efficiently spread out in space. The second panel in Figure 7 provides a different perspective on urbanization and electoral bias by plotting the simulation results against the extent to which the state has urbanized since 1950, suggesting that the Democrats face the most inefficient geographic support distributions in states that have experienced the most urbanization.

Next, we compare the bias generated by our simulated plans to that created by the districting plans that were in place both before and after the 2002 redistricting cycle. To calculate the latter, we superimpose the actual legislative district boundaries on the November 2000 precinct-level presidential election results and aggregate Bush and Gore votes, then apply the uniform swing in order to examine the share of districts that would be won by Bush in a hypothetical tied state legislature election. In Figure 8, this quantity is plotted on the vertical axis, and the simulated Republican seat shares are plotted on the horizontal axis, with lower chambers displayed in red and the upper chambers in blue.

The positive correlation between the simulation estimates and those based on actual districts suggests the strong ability of our simulations to predict the direction and extent of electoral bias across states. In general, the states where the simulations produced large pro-Republican bias, like Texas and Pennsylvania, are the same states where the actual districting plans produced similar bias. As with the simulations, observed electoral bias in these states tends to favor Republicans, sometimes quite dramatically so.

Figure 8 plots include a 45-degree line, such that any observation above (below) the line indicates that the observed pro-Republican bias associated with the existing plan exceeds (falls short of) the bias found in our raceand partisan-blind simulations. Most of the districting plans are clustered fairly close to this 45-degree line, suggesting that in most states, observed 

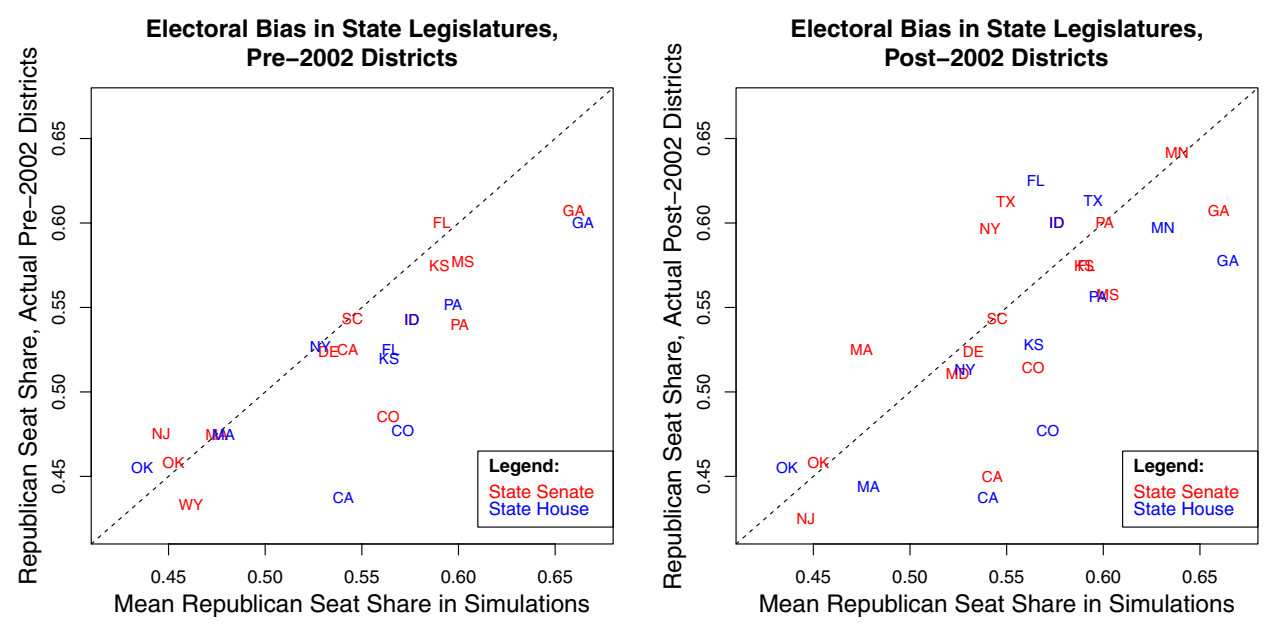

Figure 8. Electoral bias in simulated districting plans versus actual districting plans.

Note: In both plots, the horizontal axis plots estimates of the share of seats in the legislature that would have Republican majorities from districting simulations under the hypothetical scenario of a tied statewide 2000 presidential vote. Also using 2000 presidential results, the vertical axis plots the percent of seats that would be won by Republicans after applying the uniform swing to votes aggregated to the level of actual districting plans. Each measure is displayed separately for the upper and lower chambers of each state's legislature.

electoral bias would not necessarily disappear in the absence of intentional partisan and racial gerrymandering. Moreover, the 45-degree line provides a useful benchmark against which to compare observed districting plans. For instance, the plans drawn by Democrats in California and Georgia are friendlier to Democrats than the average of the simulated plans. Yet, in a state like Georgia, where the simulations reveal an especially bad geography for Democrats, even an aggressive pro-Democratic gerrymander was unable to completely erase the built-in pro-Republican bias. The simulations also identify cases, like the Florida House of Representatives and the Texas State Senate, where Republican cartographers appear to have done better for themselves than would be predicted from the simulations.

We must stop short of characterizing the deviation from the 45-degree line in Figure 8 as a measure of partisan gerrymandering because this deviation is also driven by a variety of factors including court interventions and efforts at racial representation. Nevertheless, automated districting simulations place 
observed plans into useful perspective. If one encounters a districting plan characterized by 7 or $8 \%$ pro-Republican bias in a state like Georgia or Pennsylvania, one cannot necessarily infer that partisan manipulation has taken place. Nor can one necessarily infer that efforts at minority representation are to blame, because party- and race-blind simulations produce even larger levels of bias.

On the other hand, in a state like New Jersey, Democrats are evenly dispersed throughout an urban corridor that lacks a sprawling and heterogeneous rural periphery, thus avoiding the phenomenon described in the Florida example above. As a result, the simulations predict modest proDemocratic bias in New Jersey, and this is reflected in the actual adopted plans. If Republicans in New Jersey and neighboring Pennsylvania submitted plans that produced an identical $10 \%$ bias in their favor, claims of partisan manipulation should carry more weight in New Jersey.

\section{Discussion}

This article has demonstrated that in contemporary Florida and several other urbanized states, voters are arranged in geographic space in such a way that traditional districting principles of contiguity and compactness will generate substantial electoral bias in favor of the Republican Party. This result is driven by a partisan asymmetry in voters' residential patterns: Democrats live disproportionately in dense, homogeneous neighborhoods in large cities that aggregate into landslide Democratic districts, or they are clustered in minor agglomerations that are small relative to the surrounding Republican periphery. Republicans, on the other hand, live in more sparsely populated suburban and rural neighborhoods that aggregate into districts that are geographically larger, more politically heterogeneous, and moderately Republican. We have explained how these geographic patterns can explain a large part of the pro-Republican bias observed in recent legislative elections in Florida and several other states.

Together, our theoretical explanation and our simulation results contribute to the literature on legislative districting and electoral bias in three ways. First, we have built upon and extended the work of political geographers who have noticed that electoral bias emerges in two-party systems when one party's voters are more concentrated in space. For example, Gudgin and Taylor (1979) show that in a competitive two-party system, if 
the cross-district support distributions of the two parties are skewed, the party with too many of its supporters packed into the districts of the tail of the distribution will suffer in the transformation of votes to seats. Writing in the 1970s about Britain, they conjecture that due to the inevitability of densely packed support in coalfields and manufacturing districts, the Labour Party faced a right-skewed support distribution, causing it to suffer from a less efficient transformation of votes to seats than the Conservatives. Rydon (1957) and Johnston (1976) provide similar descriptive accounts of pro-Conservative electoral bias in Australia and New Zealand, respectively.

Erikson (1972, 2002), Jacobsen (2003), and McDonald (2009a, 2009b) have made similar observations about the relative concentration of Democrats in urban U.S. House districts in the post-war period. However, perhaps because the process of redistricting is typically more politicized in the United States than in Commonwealth countries, the U.S. literature tends to focus overwhelmingly on the partisan and racial motivations of those drawing the lines. This article has attempted to provide a window into the role of human geography in U.S. electoral bias through the use of automated simulations. It shows that pro-Republican bias can be quite pronounced even in the absence of intentional gerrymandering, and is greatest in states where Democratic voters are more geographically concentrated than Republican voters. A goal for future research is to complete simulations for all 50 states, and develop more sophisticated explanations for cross-state and time-series variation in the partisan bias owing to human geography.

Second, our findings show that voter geography confounds the traditionally hypothesized relationship between gerrymandering and the partisan control of legislatures. Past scholars have taken sharp positions in favor (e.g., Carson et al., 2007) and against (Abromowitz et al., 2006; Mann, 2007; McCarty et al., 2009) the hypothesis that gerrymandering affects polarization in the House of Representatives, and scholars have also examined the impact of gerrymandering on the incumbency advantage (Friedman and Holden, 2009). Other studies have analyzed the effect of racial gerrymandering (e.g., Hill, 1995; Shotts, 2001, 2003) and respect for municipal boundaries (e.g., McDonald, 2009b) on electoral bias.

Our findings caution that the relationships between intentional gerrymandering and observed electoral bias are not necessarily identical across different states. Rather, the nexus between districting strategies and partisan control of legislatures is confounded by the electoral bias that emerges from underlying residential patterns in each state. Because geographic patterns 
of Democratic voter concentration vary widely across states, each state has a different baseline partisan seat distribution that would emerge under a districting process without overt gerrymandering. Hence, our work suggests the possibility that each state's unique voter geography may either open up or restrict opportunities for mapmakers wishing to implement politically motivated gerrymandering strategies. Simulation results like those presented in this article might provide a useful baseline for future empirical studies.

Third, our simulation results offer insight into the likely effect of various redistricting reforms, such as Amendments 5 and 6 in Florida, that attempt to mandate the seemingly objective districting criteria of compactness, contiguity, and respect for municipal boundaries. Our simulation method mimics the type of districting process mandated by such reforms. Our results suggest that in Florida, New York, Pennsylvania, and other urbanized states with substantial rural peripheries, such reforms are likely to lock in a powerful source of pro-Republican electoral bias that emanates from the distinct voter geography of these states. Hence, our simulations suggest that reducing the partisan bias observed in such states would require reformers to give up on what Dixon (1968) referred to as the "myth of non-partisan cartography," focusing not on the intentions of mapmakers, but instead on an empirical standard that assesses whether a districting plan is likely to treat both parties equally (e.g., King et al., 2006; Hirsch, 2009).

Although presidential and statewide elections have been quite close over the last decade, the Republicans have consistently controlled between 60 and $70 \%$ of the seats in Florida's state legislature and Congressional delegation. Beyond the electoral bias in the transformation of votes to seats that we illustrate in this paper, Ansolabehere et al. (2012) describe another, more subtle impact of the asymmetric distribution of partisans across districts. It is conceivable that because of the extent to which liberals are packed into urban districts, the Democratic platform, or at least its perception by Florida voters, is driven by its legislative incumbents - a small group of leftists from Miami-Dade and Broward counties who never face Republican challengers - which in turn makes it difficult for the party to compete in the crucial moderate districts. This hypothesis may help to explain why the Democrats consistently receive higher vote shares in presidential than in state races.

It is striking that political geography can turn a party like the Florida Democrats, with a persistent edge in statewide registration and presidential voting, into something approaching a permanent minority in legislative 
races. One might imagine that a future Supreme Court would entertain the notion that this situation reaches the rather high bar for justiciability of partisan gerrymandering laid out in Davis v. Bandemer (1986), where a gerrymander must be shown to have essentially locked a party out of power in a way that frustrates "the will of the majority." The recent opinions of the pivotal justices, however, suggest that a claimant would need to demonstrate that an "egregious" gerrymander is intentional. Proving such intent in court will be difficult in states where equally egregious electoral bias can emerge purely from human geography.

\section{References}

Abramowitz, A. I. 1983. "Partisan Redistricting and the 1983 Congressional Elections." Journal of Politics 45(3): 767-770.

Abramowitz, A., B. Alexander, and M. Gunning. 2006. "Incumbency, Redistricting, and the Decline of Competition in U.S. House Elections." Journal of Politics 68(1): $75-88$.

Altman, M. 1998. "Modeling the Effect of Mandatory District Compactness on Partisan Gerrymanders." Political Geography 17(8): 989-1012.

Altman, M. and M. McDonald. 2009. "BARD: Better Automated Redistricting." Journal of Statistical Software 10(2): 2-36.

Altman, M. and M. McDonald. 2004. "A Computation-Intensive Method for Evaluating Intent in Redistricting." Prepared for the 2004 Annual Meeting of the Midwest Political Science Association.

Anselin, L. 1995. "Local Indicators of Spatial Association." Geographical Analysis 27(2): 93-115.

Ansolabehere, S., W. Leblanc, and J. M. Snyder, Jr. 2012. "When Parties Are Not Teams: Party Positions in Single Member District and Proportional Representation Systems." Economic Theory 49(3): 521-547.

Brace, K., B. Grofman, L. Handley, and R. Niemi. 1988. "Minority Voting Equality: The 65 Percent Rule in Theory and Practice. Law 8 Policy 10(1): 43-62.

Cain, B. 1985. "Assessing the Partisan Effects of Redistricting." American Political Science Review 79(2): 320-33.

Cameron, C., D. Epstein, and S. O'Halloran. 1996. "Do Majority-Minority Districts Maximize Substantive Black Representation in Congress?" American Political Science Review 9(4): 794-812.

Carson J., M. Crespin, C. Finocchiaro, and D. Rohde. 2007. "Redistricting and Party Polarization in the U.S. House of Representatives." American Politics Research 35(6): 878-904.

Cirincione, C., T. Darling, and T. O'Rourke. 2003. "Assessing South Carolina's 1990s Congressional Districting." Political Geography 19(2): 189-211.

Cox, G. W. and J. N. Katz. 2002. Elbridge Gerry's Salamander: The Electoral Consequences of the Reapportionment Revolution. Cambridge: Cambridge University Press.

Dixon, R. G. 1968. Democratic Representation: Reapportionment in Law and Politics. New York: Oxford.

Erikson, R. 1972. "Malapportionment, Gerrymandering, and Party Fortunes in Congressional Elections." American Political Science Review 66(4): 1234-1245.

Erikson, R. 2002. "Sources of Partisan Bias in U.S. Congressional Elections: An Update Stimulated by Ron Johnston's Essay." Political Geography 21: 49-54. 
Fenton, J. H. 1966. Midwest Politics. New York: Holt, Reinhart and Winston.

Friedman, J. N. and R. T. Holden. "The Rising Incumbent Reelection Rate: What's Gerrymandering Got To Do With It?" Journal of Politics 71: 593-611.

Gilligan, T. W. and J. G. Matsusaka. 1999. "Structural Constraints on Partisan Bias Under the Efficient Gerrymander." Public Choice 100(1-2): 65-84.

Griggs, D. and J. Katz. 2005. "The Impact of Majority-Minority Districts on Congressional Elections." Unpublished Paper, California Institute of Technology.

Grofman, B. and G. King. 2007. "The Future of Partisan Symmetry as a Judicial Test for Partisan Gerrymandering after LULAC v. Perry." Election Law Journal 6(1): 2-35.

Gudgin, G. and P. J. Taylor. 1979. Seats, Votes, and the Spatial Organisation of Elections. London: Routledge.

Gul, F. and W. Pesendorfer. 2010. "Strategic Redistricting." American Economic Review 100(4): 1616-1641.

Herron, M. and A. Wiseman. 2008. "Gerrymanders and Theories of Law Making: A Study of Legislative Redistricting in Illinois." Journal of Politics 70(1): 151-167.

Hill, K. A. 1995. "Does the Creation of Majority Black Districts Aid Republicans? An Analysis of the 1992 Congressional Elections in Eight Southern States." Journal of Politics 57(2): 384-401.

Hirsch, S. 2003. "The United States House of Unrepresentatives: What Went Wrong in the Latest Round of Congressional Redistricting." Election Law Journal 2(2): 179-216.

Hirsch, S. 2009. "A Proposal for Redistricting Reform: A Model State Constitutional Amendment." Paper presented at American Mathematics Society, Washington, DC, January 8, 2009.

Jacobson, G. C. 2003. "Terror, Terrain, and Turnout: Explaining the 2002 Midterm Elections." Political Science Quarterly 118(1): 1-22.

Johnston, R. J. 1976. "Spatial Structure, Plurality Systems and Electoral Bias." Canadian Geographer 20: 310-328.

Johnston, R. J. and C. A. Hughes. 2008. "Constituency Delimitation and the Unintentional Gerrymander in Brisbane." Australian Geographical Studies 16(2): 99-110.

King, G. and A. Gelman. 1991. "Systemic Consequences of Incumbency Advantage in U.S. House Elections." American Journal of Political Science 35(1): 110-138.

King, G., B. Grofman, A. Gelman, and J. Katz. 2006. Brief of Amicus Curiae filed in LULAC v. Perry.

Lublin, D. 1997. The Paradox of Representation: Racial Gerrymandering and Minority Interests in Congress. Princeton, NJ: Princeton University Press.

Mann, T. E. 2007. "Polarizing the House of Representatives: How Much does Gerrymandering Matter?" In Red and Blue Nation? Characteristics and Causes of America's Polarized Parties, Pietro S. Novolo and David W. Brady, eds. Stanford, CA: Hoover Institution, pp. 263-283.

McCarty, N., K. T. Poole, and H. Rosenthal. 2009. "Does Gerrymandering Cause Polarization?" American Journal of Political Science 53(3): 666-680.

McDonald, M. 2009a. "Seats to Votes Ratios in the United States." Unpublished Paper, George Mason University.

McDonald M. 2009b. The Midwest Mapping Project. Fairfax, VA: George Mason University Press.

McDonald, M. D. and R. L. Engstrom. 1989. "Detecting Gerrymanders. In Toward Fair and Effective Representation: Political Gerrymandering and the Courts, ed. Bernard Grofman. New York, NY: Agathon, pp. 178-202.

Nagel, S. S. 1965. "Simplified Bipartisan Computer Redistricting." Stanford Law Review 17(5): 863-869.

Rodden, J. 2010. "The Geographic Distribution of Political Preferences." Annual Review of Political Science 13: 297-340. 
Rydon, J. 1957. "The Relation of Votes to Seats in Elections for the Australian House of Representatives 1949-54." Political Science 9: 49-65.

Shotts, K. 2001. "The Effect of Majority-Minority Districts on Partisan Gerrymandering." American Journal of Political Science 45(1): 120-135.

Shotts, K. 2003. "Does Racial Redistricting Cause Conservative Policy Outcomes? Policy Preferences of Southern Representatives in the 1980s and 1990s." Journal of Politics 65(1): 216-226.

Taylor, P. J. and G. Gudgin. 1976. "The Myth of Non-Partisan Cartography: A Study of Electoral Biases in the English Boundary Commission's Redistribution for 1955-1970." Urban Studies 13(13): 13-25.

Vickrey, W. 1961. "On the Prevention of Gerrymandering." Political Science Quarterly 76(1): 105-110.

Weaver, J. B. and S. W. Hess. 1963. "A Procedure for Nonpartisan Districting." Yale Law Review 72(2): 228-308.

Wildgen J. and R. Engstrom. 1980. "Spatial Distribution of Partisan Support and the Seats/Votes Relationship." Legislative Studies Quarterly 5(3): 423-436. 